\title{
Leveraging Relationships to Get Ready For Change ${ }^{1}$
}

\author{
Prof. Paula Jarzabkowski, Dr Michael Smets and Dr Paul Spee
}

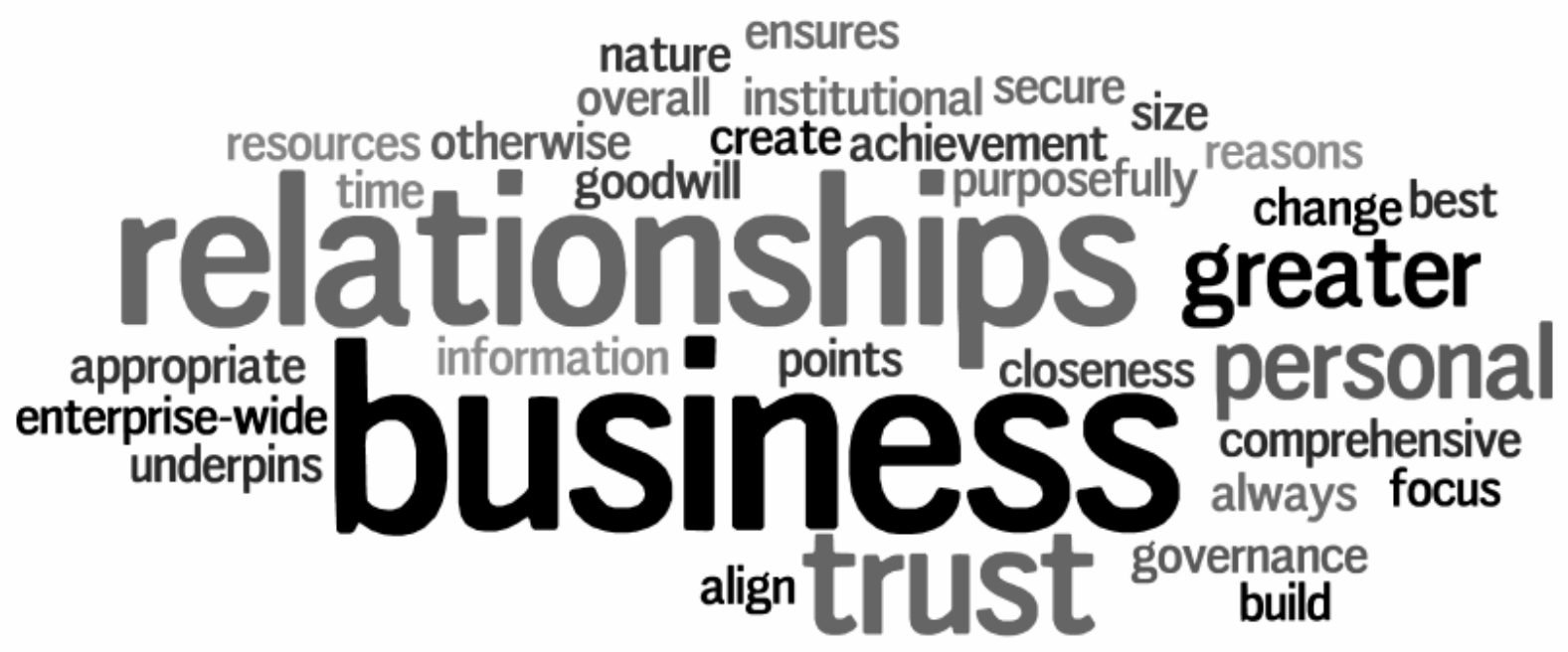

Four strategies towards key external relationships to effectively implement strategic change

\section{Introduction}

At its most fundamental, businesses are built by establishing relationships with customers. Such relationships enable you to capture more of their patronage by better evaluating and servicing their needs. High volume industries with fragmented customers, such as supermarkets and other retailers of fast-moving consumer goods can use rich purchasing data points and information technology to develop customer relationship management systems based on mass customization. They need little actual contact with consumers to understand their needs and buying patterns, to better understand how to secure more of their spend. Much has been written about these industries, and about how they can capture value through advanced customer relationship management systems.

By contrast, industries that are characterised by relatively low volume but often high value transactions with a limited number of market ...deep knowledge of clients, 'relationship-intensive' industries participants (such as professional service firms, many investment-based financial services and the reinsurance industry) require deep knowledge of clients in order to evaluate the quality of their business proposition and tailor packages to their often complex needs. We term these 'relationship-intensive' industries because deep relationships that involve significant investment of time and resources are critical to establish and maintain the basis for

\footnotetext{
${ }^{1}$ The authors gratefully acknowledge support from the following bodies in conducting the research that informs this chapter: The Insurance Intellectual Capital Initiative; the Economic \& Social Research Council: RES-173-27-0163; RES-186-27-0020; British Academy: SG091192
} 
doing business. Less has been written about effective relationship management to add value and support growth and change in such industries. This chapter is a contribution to stimulate that end

$\left(\begin{array}{c}\text {...personal contact tacitly informs } \\ \text { strategic thinking }\end{array}\right)$ conferences and social outings like golf days, sport events and theatre visits all enable the development and maintenance of relationships. While these events can be pleasant, they are also time-consuming, involving a small number of key people within the company whose time is a scarce resource. The point of all this personal contact is to garner valuable information and gain impressions that tacitly inform strategic thinking about the business relationship. As these relationships are also personal, often developed through prolonged contact and trust between specific individuals; it can therefore be hard to distinguish between a quality business relationship and a good personal relationship. Additionally, much relationship behaviour is tacit, unrecognised by the individuals in question even as they forge and maintain relationships and make business decisions based on them.

It is thus critical to develop a strategic approach to relationship management in relationship

$$
\lceil
$$

...how to take a strategic, portfolio-based approach to corporate relationships intensive industries that both identifies the best
ways to meet, and which levels of strategic
decision maker in the company should be meeting
in different situations. A strategic approach can
help to distinguish between clients and allocate

firm resources appropriately to support the development of a portfolio of business relationships that align with the firm strategy and appetite for growth or change.

In this chapter, we offer recommendations for managers in relationship-intensive industries to think more deeply about how to take a strategic, portfolio-based approach to their corporate relationships. We will illustrate our chapter with examples from our 2-year global study of the major players in the reinsurance industry - a relationship-intensive finance sector industry. We offer a framework to think systemically about business-to-business relationships and to manage them in ways that support current and future business, particularly in relationship intensive industries, that are based on deep and often personal relationships with a relatively small number of market participants.

Such relationships are often based on personal contact that builds trust. We shall first unpack the association between trust and information quality, in order to provide greater insight into how being selective about relationship activities can support information and help to build trust in business relationships. We will then introduce the two key dimensions of our framework, which are (1) long term business value and (2) information quality. These two form a matrix of four distinct relationships that should be managed very differently. It is 
critical to understand what type of relationships you want to have, with whom, and how that relationship is best managed. We will use the information-value matrix to outline how to establish a portfolio approach to managing business relationships for growth and change.

\section{Case examples - that contextualise our recommendations}

The global reinsurance industry is both an important sector in its own right and one with application to other relationship-intensive industries and services. The reinsurance market is of great economic significance with reinsurance companies holding invested assets of some US\$ 927 billion in stock markets (IAIS, 2009). It also has great social significance, supporting the pricing and protection of insurance cover for the policy-holding public at large. Reinsurance is effectively the insurance of insurance companies. Reinsurance markets enable insurance companies to better leverage their capital by providing financial cover in the event of a big loss, such as hurricanes, floods and terrorism that involve large-scale insurance claims. This lowers the cost of capital for insurance companies, helps to keep direct insurance prices more affordable and ensures the liquidity of insurers to pay-out in the wake of a loss. For example, in recent world events, such as the 2010 oil leak in deepwater horizon, the earthquakes in Chile (2010) and New Zealand (2011), or the 2011 tsunami in Japan, the reinsurance industry underwrote significant proportions of the risks that insurance companies had taken. The reinsurance sector paid out for much of the losses experienced.

Global reinsurance markets represent an ideal context in which to study relationship management. Reinsurance firms must make judgements and allocate significant capital to high-value, high-severity risks, such as earthquakes, hurricanes and floods, where the quality of information and probability of events is uncertain and difficult to model accurately. Hence, in addition to quantitative modelling, reinsurance underwriters are continuously looking for 'soft' information to supplement their knowledge of the risks they are underwriting and their confidence in their clients: the insurance companies that they are underwriting. In turn, the insurance companies that are clients are looking not only to purchase risk cover at a good price, but to know that the reinsurers they are working with will be both financially solvent and willing to meet their commitments to pay claims in the event of a major and unpredictable loss, such as a tsunami. Both business parties are thus looking to establish deep relationships that provide information about and trust in each other. They gain this information through a protracted decision-making process that involves multiple opportunities for reinsurers and clients to meet at conferences, on site visits to the insurance premises, on road-shows, where the clients visit their reinsurers, and at social events such as golf days, sailing and ski trips, dinners. At these meetings, managers at different levels from underwriters to CEOs meet to discuss business, socialize and, often meet each other's partners. The aim of these meetings is to develop sticky, long-term relationships that can be sustained over many years, providing reinsurance cover in both good and bad years. As the $\mathrm{COO}$ of a leading reinsurance company notes about his meetings with key insurance clients: 
"If you are friends, it's very nice. We have friends in the industry but we try to keep that separate. I could spend three months a year sailing, golfing and skiing because of the invitations I get but we normally don't accept. We're talking about business; it's a serious thing and we are exposing a lot of money from our shareholders and our decisions are not based on who is giving you the best golfing experience. It's based on a business relationship and that is important for us. We make sure that someone at senior management level visits the senior management of our key clients around the globe at least once a year. All that this is doing really is ensuring there is sufficient

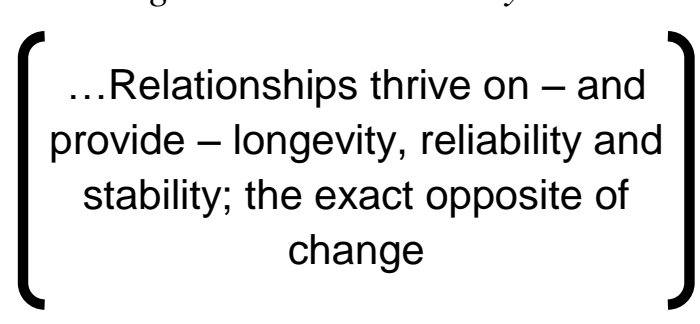

\section{Trust or Information?}

At first glance, using relationships to get ready for change seems odd. Relationships thrive on - and provide - longevity, reliability and stability; features of our lives that are the exact opposite of change. Relationships make the future seem a little bit more certain and foreseeable. In a relationship, what is to come seems more likely to be like what has gone before, which is a comforting idea in a turbulent business environment in which tomorrow rarely looks much like yesterday and we are forced to adapt to change at an ever increasing pace. But maybe it is that idea of comfort that is the problem when we come to think about relationships from a business perspective - and in the context of getting ready for change.

At a closer look, relationships are not only a good instrument for making (business) life more predictable and reducing the need to adapt. They are also a great tool for shaping the future, which allows those who use it skilfully to proactively shape their future business environment. Rather than adjusting reactively to the future, why not shape a brighter future by building it with existing relationships? These relationships can involve a variety of stakeholders, such as suppliers, staff, competitors, or regulators. The most critical, however, are relationships with one's customers. It is critical to establish a picture of the future that

... good relationship management is about creating a joint and coherent understanding of what the future will and should look like for mutual organisational business benefit resonates with their needs and to build your growth and strategic portfolio around these client relationships. In order to create a desirable future, you need to understand what customers need (now) and how to adapt (reactively), but equally and more importantly, to appreciate what customers are

likely to need in future and to shape that future (proactively). Essentially, good relationship management is about creating a joint and coherent understanding of what the future will and should look like for mutual organisational business benefit. Hence, whatever your time horizon and however radical the change you may consider, you can use your relationships to get ready for it. 
Relationships come in a variety of shapes and sizes. Instinctively, all of us maintain a host of personal relationships with families and friends and many business relationships start from a personal link. Therefore, it is not surprising that many people take their understanding of personal relationships into business, particularly when the business context for relationshipintensive industries provides many opportunities to develop personal relationships between decision-makers in client and supplier businesses.

A number of industry-based events are specifically designed to develop personal contacts between key operatives. For example, there are industry conferences in exciting locations that are conducive to developing personal as well as professional contacts. In the reinsurance industry, there are annual global conferences held in Monte Carlo, Baden-Baden and different venues in the USA, as well as more regional events at which the key players gather to discuss business, drink champagne, attend cocktail parties, dine, play tennis and golf and develop not only market knowledge but also personal relationships. These conferences are only one point of contact each year. There are also meetings between clients and reinsurers in each other's offices, at which detailed questions about business practices, financial management and strategy can be examined. Such meetings are often followed with lunch or dinner, to further the relationship. Additionally, there are various forms of corporate entertainment offered by suppliers, from corporate boxes at key sporting events, to ski trips, golf days, sailing and theatre tickets, at which the managers of client and supplier firms can socialize.

At these various meetings, both parties gain an impression that they 'know' each other and this knowledge provides some reassurance about the quality of both the people in the business and the business itself. The value of such meetings is often expressed as "When you spend time with someone over golf and dinner, you get to know what he is really like, whether you trust him, much more than if you just meet in the office to talk about business". At the same time, much of business is based on generating a positive feeling towards a client or supplier. These meetings provide people with an opportunity to find out whether they like each other; "At the end of the day, people are going to do more business with people they like”. Thus, opportunities for meeting not only provide an opportunity to gain business information, but also to develop positive feelings and liking for business partners. This liking is perceived to be valuable and is often expressed as: "I know him"; "He's a good guy"; "I trust him".

While such meetings undoubtedly do add value and can be very important in the strategic formation of relationships, often people are confusing the dimension of personal liking with the purpose of business relationships and the $\left(\begin{array}{c}\text {...people confuse personal liking } \\ \text { with the purpose of business } \\ \text { relationships }\end{array}\right)$ different ways that they add competitive advantage. It is important for managers to understand that perceptions of liking and trust are actually grounded in informational ...Trust it critical to business properties, which can be developed in many ways, not all of which are dependent on personal 
$\left.\begin{array}{c}\text {...three important informational } \\ \text { aspects to this trust: (1) personal, } \\ \text { (2) processual and (3) } \\ \text { institutional. }\end{array}\right\}$ relationships. Trust is critical to business relationships and is likely to be developed through repeated, long-term engagement. However, the real basis of this trust is not based on the personal likability of the respective managers, but on trust

in their business practices and their business context.

When we unpacked what managers in relationship-intensive business were saying when they talked about trusting, knowing and liking particular business partners, we found that there are three important informational aspects to this trust: (1) personal, (2) processual and (3) institutional. These three aspects should not be confused as they indicate different approaches to, and reasons for, business relationships. Successful companies are those that know how to exploit business relationships according to these different informational aspects of trust, Explore this with us.

\section{Trust as a proxy for information}

When clients and suppliers meet, they are each looking for information on which to evaluate the other and, importantly, the viability of the other's business, and their suitability for a business relationship. Much of this information is conveyed personally and, so, is equated with personal trust and liking. However, while quality information on a partner is indeed a good basis for trust, there are many ways that information can support the development of trust, not all of which is grounded in personal liking. Our research indicates that there are three types of trust with unique informational properties; (1) personal or goodwill trust, (2)

$$
\text { \...personal or 'goodwill trust' }\} \begin{aligned}
& \text { processual trust and (3) institutional trust. Not all } \\
& \text { of them are dependent on personal relationships. } \\
& \text { Rather, we like to think of these as three }
\end{aligned}
$$

complementary lenses that progressively zoom out from the personal relationship to the wider business context.

\section{$\left(\begin{array}{c}\text {...impressions of trustworthiness } \\ \text { on personal 'likability' }\end{array}\right\}$}

First there is personal or 'goodwill trust'.

Traditionally, in business relationships, personal ties play a strong role. In personal relationships we intuitively base impressions of trustworthiness on personal 'likability'. Getting to know each other over drinks, dinner, golf and sailing provides an opportunity to develop personal knowledge and liking; quite simply, managers will not want to spend as much time on social activities with people that they do not like. Likeability and personal knowledge therefore provide a good initial point for a business relationship. Furthermore, they are enhanced by repeat behavior. That is, the longer the relationships last, the more we trust the people with whom we have those relationships. We have faith that they will prioritize the common good of the relationship over some self-interested benefit they might otherwise gain. This is the essence of trust. In long-term business relationships, goodwill trust is thus not just about personal likability but is also based on information, built up over the life-time of the relationship, about the transparency with which a business partner acts 
and their honesty in past behaviours. It may supplement the other forms of trust described below.

Generic belief in a person's benevolence or likability is not, on its own, sufficient for a good business relationship. As one Lloyd's CEO put it; "Some people want to prolong relationships. You get to know them quite well and there becomes this sort of bond and almost friendship. There's an element of potential protectionism in there of one's mates" (CEO, Lloyd's Reinsurance Firm). History is full of lovable rogues and there is no shortage of charismatic conmen in the recent and current business context. Thus we need to recognize that trust depends on a range of ways to access high-quality information about the business partner. This is particularly important as personal relationships are displaced by corporate relationships in an increasingly competitive, accountable and regulated business environment. Understanding that trust in a business relationship is essentially a proxy for high-quality information about business behaviour directs attention to other forms of trust, decoupled from personal likeability, and information that exist in business relationships.

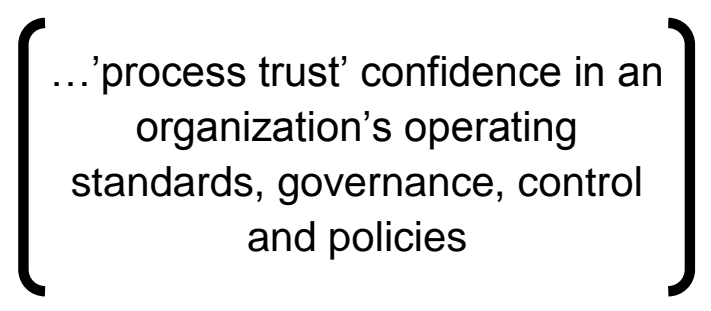

A second dimension is 'process trust', that is confidence in an organization's operating standards, governance, controls and policies. This view on trust and information zooms out from the personal relationship and anchors trust in the context of the organization. Process trust addresses two fundamental questions. First: 'Does the organization actually have the capability to deliver on the commitment that the individual made on its behalf?', and second: 'If the individual was inclined to cheat or be dishonest in the relationship, how likely is it that organizational policies or structures will protect against that?' By asking these questions, organizational characteristics such as governance, financial management and oversight come into view. For example, in business meetings, reinsurers typically ask prospective insurance partners about their underwriting procedures, claims management practices, strategies for growth and financial security. Furthermore, we observed that smart reinsurers used this information to grade firms on the quality of their organizational practices; " ... understand the company, understand what they do and understand how they do it, how they make decisions, get inside how they underwrite, how they select risks, how they adjust claims, what risks they're taking on and how they're taking those risks on" (Chief Underwriting Officer, Lloyd's Reinsurance Firm). Such information can be obtained through personal contact, but it does not necessarily involve golf or drinks. Rather, a site visit, detailed discussion of the current firm position and any recent loss history, and some auditing of the prospective partners' books - such relational activities are more likely to provide information that supports process trust. Where this information suggests trustworthy practices and procedures, there is less need to base business decisions on your assessment of the personal qualities of your counterpart; you can put your faith in the company's processes to deliver good results. Your business partner may be a teetotaller with different personal and social interests to you. But even 
...'institutional trust' legal and political systems, professional standards or reputational networks would discourage dishonest behaviour someone you find socially boring could run a tight company with which you wish to do business.

Lastly, to predict current and future behaviour, you can zoom out further and look at the institutional context in which your partner organization operates. This perspective can instil 'institutional trust' in a relationship based on the judgement that legal and political systems, professional standards or reputational networks would discourage dishonest behaviour. For example, people prefer to do business with partners in countries that have low corruption, stable political systems and regulatory policies that provide reasonable standards of assurance about business practices. Furthermore, it is preferable to do business in contexts where public information is of good quality and easily available, because of information standards. Such contexts provide some surety about the quality of information you can access about a business partner and also indicate the minimum standards with which a partner company will comply. Examples of such institutional trust sources are rating agencies that independently assess the creditworthiness of organizations or government databases on insured risks. Both provide independent, verifiable information on whether a borrower can be trusted to repay his debt or, respectively, whether a portfolio of insurance policies is actually worth what an insurer claims. For example, much of North America and Western Europe have consistent, fine-grained publically available information on insured properties, and insist on corporate governance standards. These regions have robust regulatory systems that subject companies to scrutiny and provide retribution for those that fail to comply. Indeed, one of the key insurance markets, Lloyd's of London, derives much of its reputational assets from the strong financial and regulatory assurance that underpin membership in Lloyd's; an insurance company cannot operate out of Lloyd's without meeting these standards. While there are bound to be relatively stronger and weaker companies within Lloyd's, a reinsurer may be

$$
\text { I }
$$$$
\text { ...trust is really a proxy for }
$$
information assured that any Lloyd's insurance company has at least acceptable operating standards and robust financial and regulatory backing.

Adopting such a multi-faceted understanding of trust, has two benefits: First, it makes clear that trust is really a proxy for information. The close link between relationships and information however has not often been made explicit. If, so far, to try and predict future behavior you have relied on past experience and your trust in your business partner as a person, think how much more accurate and reliable your predictions could be if you deliberately included the organizational and institutional context in your assessment. Second, if you orient your relationship management towards acquiring more information about what your customer values, how the firm operates and what institutional networks it is tied into, you get much closer to sensing the 'next big thing' on their agenda. For example, a good insurance client, with tight organizational processes and a strong portfolio in stable markets is a good bet to work with when they penetrate emerging markets. Similarly, in markets where the institutional context does not inspire confidence, a strong knowledge of specific insurer's organizational processes can help with selecting the best clients in such markets and learning 
how best to operate within that market. As a senior executive at one leading reinsurer notes, the longer you work with such clients, the more that you can benefit from mutual learning and information exchange, and that facilitates a stronger business relationship; "It's two-way. They need to know that you're partnering with them but for you to do that, you need to really understand them. We're getting to that level of dialogue which isn't one-way; 'it's come and help me with my business plan. Does it look sensible? What are the risks that I can run?' And it's that sort of dialogue which is superb. That's where we want to be" (Global Account Executive, European Reinsurance Firm).

To position your firm for the future and get ready for change, you should shift the focus from interpersonal relationships to business relationships at the corporate level with a view to gaining and sharing information that helps to create a desirable future with the client.

\section{Appraising relationships: The information-value matrix}

Relationship management is time-intensive and costly, but can also be a very valuable business tool. Therefore, it is important not to indiscriminately apply the same relationship management techniques to all existing and potential clients without distinguishing exactly what a relationship can add, and how to best foster each type of relationship to gain the appropriate benefits. Let us consider how to differentiate business relationships according to their ability to provide competitive advantage, and illustrate the relationship management techniques appropriate to different relationships.

Unpacking the different types of trust according to the different types of information behind them opens up opportunities for more strategic relationship management. While it is always easy to lose someone's trust, building it up - and quickly - is very difficult. Essentially, any measure directly targeted at enhancing trust can be exposed as such and dismissed as a tactical move. Sharing information from which different forms of trust can flow is easier. A focus on acquiring and sharing information rather than developing trust strengthens the relationship and facilitates current business, but also opens up mutual learning opportunities to understand the ramifications of future business.

As different forms of information underpin different forms of trust, the management of different relationships should differ according to information availability and quality. That is why 'information quality' forms one dimension of our relationship management framework. For simplicity, we measure information quality on a 'low-to-high' continuum. If information is only accessible through personal contact, it forms the low-point. The availability of detailed, independently verifiable information, in combination with other, personal and organizational ways of accessing information comprises the maximum on the scale. The relative importance of contextual and organizational information can vary anywhere in between. 

should differ by the value you attribute to different customers. Business relationships differ from personal ones not only in the role that trust and information play, but also in the form of payback

we expect. Maintaining meaningful relationships takes a lot of effort. In this respect business and personal relationships are alike; but in business relationships we expect a measurable, value-adding pay-off. If a customer is of low value for us, it is unlikely that investment in a long-term relationship will pay off. Understanding relationship value ensures that those relationships which generate the most solid returns to a firm receive the highest levels of relationship management, including entertainment such as sailing, golf, skiing and dinner. At the same time it guards against over-investing in personal relationships and other timeintensive and costly mechanisms of relationship management where opportunities for valueadding pay-off are limited, no matter how congenial the individuals concerned.

As intuitive as it sounds that more substantial investments should focus on relationships with valuable customers, there is an easy pitfall: too often, business relationships are evaluated on the basis of current business value. This is bound to be short-sighted, especially if we want to use our relationships to get ready for change. If we want to shape a positive future business environment, we need also to team up with those customers who are likely to be valuable in future. Business prospects, recent growth rates, market potential and strategic orientation provide good indicators for which customers are likely to be valuable in future - and they need not be the ones that are valuable today.

\section{Developing a portfolio approach to business relationships}

Different types of relationships serve different purposes. One type of relationship serves the need to get good quality information in order to build a good understanding of each other. Another type of relationship exists to make ourselves more attractive to each other.

Organisations need to segment relationships on the basis of what they want/need to get out of them and then decide how they will pursue such relationships and through whom.

Consider the following tool, the relationship portfolio matrix shown in Figure 1, based on the two dimensions we have defined: information quality and relative value. The quadrants distinguish four distinct, idealised types of relationship with associated typical forms of interaction that fall into two broad categories: high engagement strategies for high value clients and low engagement relationships for low value clients. Managers can use this matrix for evaluating relationships and developing a portfolio approach to their management. 


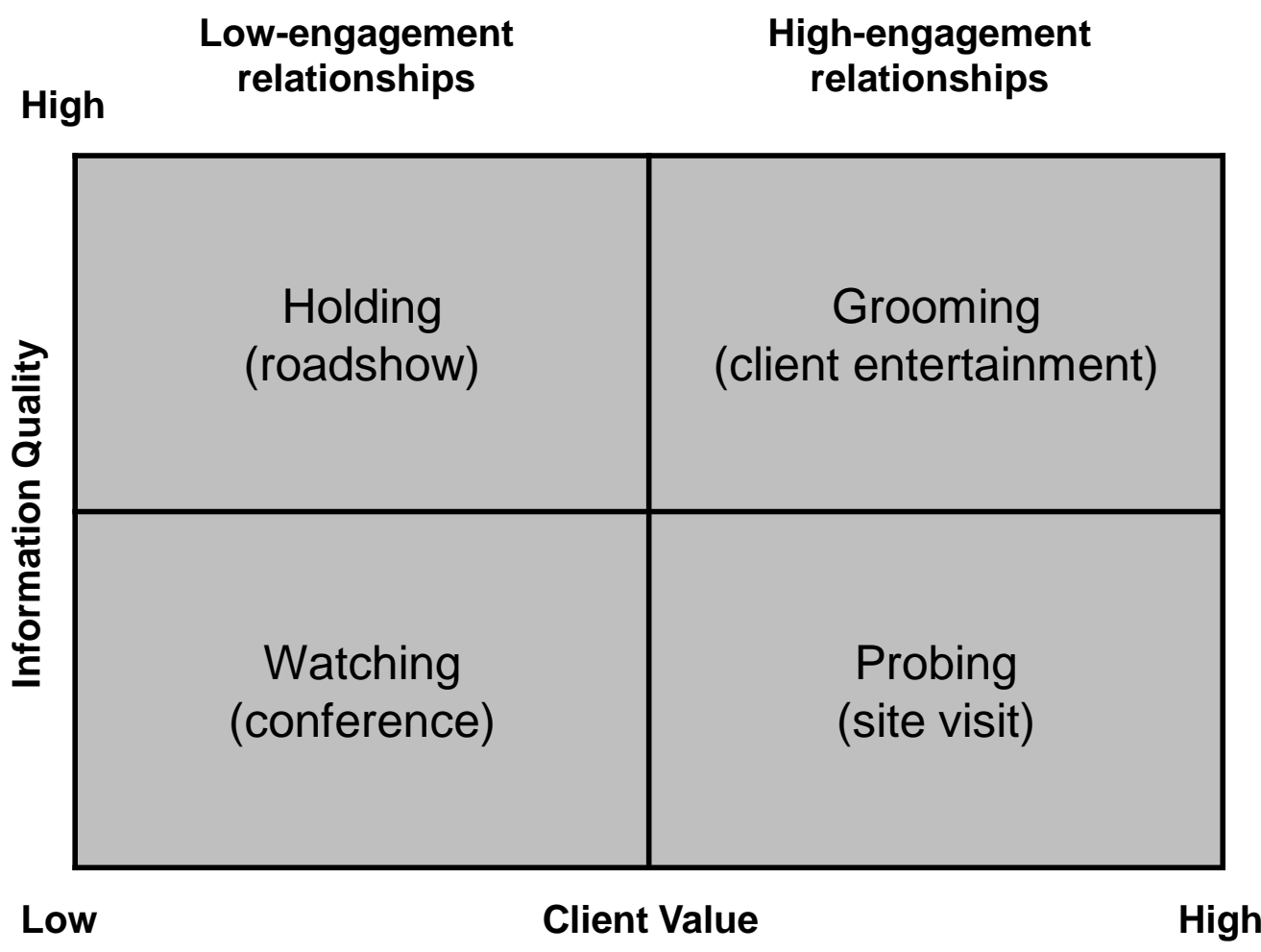

A watching relationship is appropriate for clients whose development you want to 'watch from a distance'. They might be firms in regions where institutional information is of poor quality and there is little transparency with which to assess the quality of the company's practices, or its longer term viability. Many firms in emerging markets fall into this bracket. People may know that these regions will develop, but it is hard to generate sufficient information to select particular firms to partner, and the size of current and potential business is not sufficient to invest in a closer relationship that could overcome informational deficits. Quite simply, until these clients grow in potential value or information quality, they are not worth a great deal of relationship investment. Naturally it pays to keep an eye on them, in order to spot those companies that might have potential to grow into one of the other quadrants - in particular, if they can learn to improve the quality of the information they provide they can move up the left hand side of the matrix. Meeting at one of the annual industry conferences is usually sufficient to stay appraised of the client's business development without committing serious resources. If executives target a particular emerging market as a potential area for growth, they could even attend a regional conference in that market, in order to gain information about the market and the potential players, so that they have an idea of which client firms to watch for development potential. As a Lloyd's reinsurance underwriter noted, after attending a Latin American insurance conference; "It was a useful fact-finding trip. Every client appreciated that we were there. Many of them don't travel because of financial constraints. "Such conferences are also a way for the company to signal its potential interest in that market and so flush out any clients that might have potential to grow in information or value. 
The holding relationship is typically a case of maintaining small but well managed clients that provide good business information and operate in relatively stable institutional contexts. While such clients may have limited potential for growth, each one can still be a sound bet that is profitable within its own financial parameters. These clients make up an attractive part of a portfolio, because they earn steady rents and the relationship can be maintained over many years, providing stability and predictability in the overall firm portfolio. It is important to maintain a sufficiently close relationship to profit from any change in growth or potential value. This can be done through roadshows. For example, where the insurance company visits reinsurers to explain their business portfolio and attract reinsurance funding. Such visits might be accompanied by dinner whilst the client is in town, particularly if there are any new business developments to discuss. Deeper personal engagement is inefficient because there are no information deficits to be addressed through extensive face-to-face interaction and client value does not warrant such investment: "It's an hour of talking about the business, what they've been doing in the last year, what is important in the next renewal. But if it's a client I know I don't want to grow further with, I avoid the dinner" (Chief Underwriting Officer, Bermudian Reinsurance Firm). Nonetheless, such relationships can be important in an overall firm portfolio, because each one is a small but sound piece of business and thus comprise attractive elements of a portfolio because they yield relationships of sufficient value, given their relatively low cost to maintain.

The purpose of a probing relationship is to develop sufficient confidence in large-scale, potentially valuable clients to counteract the lack of publicly available information. This type of client is likely to be one in either an unusual line of business that is less knowable or in an unknowable market place. In reinsurance, this might be credit, terror, or nuclear risks, or an insurance company in a region where it is difficult to get quality information, such as a large client in a new or emerging market, where political, legal and cultural systems are still not well understood. For example, imagine reinsuring the London Olympics for a terrorism risk. A reinsurer would want information on the security systems available, the capability for responding to and containing terror threats, the experience of the insurance company in appraising such risks, their knowledge of the potential size and scale of damage from different types of terror acts, and the possible payout. Place that same risk - a major global sporting event - in a less known global region and the informational problem is exacerbated. The purpose of a probing relationship is thus to get more granular information about the client's procedures for appraising the risks that they write. This type of relationship requires high engagement to generate information. It is best managed by visiting client premises and probing their work practices, so-called 'kicking the tyres': "I want to see the risks. I want to talk to them, meet their people, know that they know what they are doing" (Underwriter, Lloyd's Reinsurance Firm). The costly investment of time spent conducting site visits is warranted by the value of the client. 
The objective of a grooming relationship in which there is both high quality information and high value, is to 'get more of what everyone wants'; that is, to maintain or grow the share of large-scale clients doing business that is supported by good information. Where information is considered good and verifiable, such as in North American insurance firms, where finegrained data on insurance risks are widely accessible, there is less need for managers to personally probe the client's practices. However, where quality data is widely available, all players in the market can access that information to evaluate the attractiveness of the client. This is thus the business - those leading global clients that everyone wants to partner with. Here

...relationships that involve intensive personal time serve to establish personal liking and goodwill as a differentiator from other potential partners in the marketplace relationships that involve intensive personal time serve a different purpose. They are not to gain better information, but to establish personal liking and goodwill as a differentiator from other potential partners in the marketplace; "Relationships to make business more sticky are probably more important than the knowledge of the underlying risk. I think you can get that [knowledge] without a relationship" (Chief Underwriting Officer, Bermudian Reinsurance Firm). Managers should use high engagement strategies, such as golf weekends and sailing trips to 'groom' or get to know their clients better and firmly establish themselves as the partner of choice in the client's mind. Furthermore, this engagement should be multi-level, with contact between CEOs and senior executives as well as between middle managers; "We did a sailing event on the south coast of the UK just because one of our clients liked sailing" (CFO, Bermudian Reinsurance Firm). Such relationship strategies allow managers to protect and grow their participation in business with these firms. That is, high-engagement, grooming relationships can create a barrier to entry for other market players. These relationships are where corporate entertainment has its place as a legitimate tactic to exploit competitive advantage. Keeping in touch in a non-business environment is an important signal of willingness to invest in a relationship. 


\section{Summary}

There are four strategies towards key external relationships to effectively implement strategic change:

1. A watching relationship, appropriate for clients whose development you want to 'watch from a distance'.

2. A holding relationship, for small-scale clients that provide good business information and operate in relatively stable institutional contexts.

3. A probing relationship to develop sufficient confidence in large-scale, potentially valuable clients.

4. A grooming relationship in which there is both high quality information and high value, to 'get more of what everyone wants'

\section{Action Points}

Consciously select which business relationships to proactively pursue:

- That will enhance the information you have about the client organisation

- With key individuals in client organisations that present significant growth potential

- With strategic individuals in strategic organisations where rapport, personal goodwill and affinity already exist

- Where robust processes exist that enhance trust in the client organisation

- Within organisations that operate in strong institutional governance structures

- Purposefully nurturing the opportunity to create greater mutually-beneficial business gain.

- Building greater trust and enlarging the comprehensive nature of the information that underpins the business activity

- Increasing and securing the potential size of the business overall. 


\section{Self-assessment tool}

To what extent are you using the following guidelines to select which business relationships to proactively pursue? Those

\begin{tabular}{|c|c|c|c|c|c|}
\hline Attribute & Never & Sometimes & Mostly & Always & $\begin{array}{c}\text { Cumulative } \\
\text { Score }\end{array}$ \\
\hline $\begin{array}{l}\text { That will enhance the } \\
\text { information you have } \\
\text { about the client } \\
\text { organisation? }\end{array}$ & 0 & 1 & 2 & 3 & \\
\hline $\begin{array}{l}\text { With key individuals in } \\
\text { client organisations that } \\
\text { present significant } \\
\text { growth potential? }\end{array}$ & 0 & 1 & 2 & 3 & \\
\hline $\begin{array}{l}\text { With strategic } \\
\text { individuals where } \\
\text { rapport, personal } \\
\text { goodwill and affinity } \\
\text { already exist? }\end{array}$ & 0 & 1 & 2 & 3 & \\
\hline $\begin{array}{l}\text { Where robust processes } \\
\text { exist that enhance trust } \\
\text { in the client } \\
\text { organisation? }\end{array}$ & 0 & 1 & 2 & 3 & \\
\hline $\begin{array}{l}\text { Within organisations } \\
\text { that operate in strong } \\
\text { institutional } \\
\text { governance structures }\end{array}$ & 0 & 1 & 2 & 3 & \\
\hline
\end{tabular}

\section{Benchmark Scores:}

\begin{tabular}{|c|c|c|c|}
\hline $\mathbf{0 - 3}$ & $\mathbf{4 - 8}$ & $\mathbf{9 - 1 2}$ & $\mathbf{1 3 - 1 5}$ \\
\hline $\begin{array}{c}\text { In the danger } \\
\text { zone! }\end{array}$ & $\begin{array}{c}\text { Some foundations that } \\
\text { need development }\end{array}$ & $\begin{array}{c}\text { Good but room for } \\
\text { improvement }\end{array}$ & $\begin{array}{c}\text { Moving towards } \\
\text { consistent high } \\
\text { performance }\end{array}$ \\
\hline
\end{tabular}




\section{Further Reading:}

Bachmann, R. and A. C. Inkpen, 2011. Understanding Institutional-based Trust Building Processes in Inter-organizational Relationships. Organization Studies, 32.2 , 281-301

Galford, R. \& A. Seibold Drapeau 2003. The Enemies of Trust. Harvard Business Review, February

Kramer, R. M., \& Lewicki, R J. (2010). Repairing and enhancing trust: Approaches to reducing organizational trust deficits. In J. P. Walsh \& Arthur P. Brief (Eds.), The Academy of Management Annals (Volume 4), pp. 245-277.

Lewicki RJ, and Bunker BB. 1996. Developing and Maintaining Trust In Working Relationships . In: Kramer RM, Tyler TR, eds. Trust in Organizations: Frontiers of Theory. Thousand Oaks, CA, Sage Publications

Tomkins, Cyril 2001, 'Interdependencies, Trust and Information in Relationships, Alliances and. Networks', Accounting, Organizations and Society, vol 26: 161-191

Vosselman, E. and J. van der Meer-Kooistra. 2009. Accounting for control and trust building in interfirm transactional relationships. Accounting, Organizations and Society 34(2): 267283

Zucker, L. G. (1986). Production of trust: Institutional sources of economic structure, 18401920. In B. M. Staw and L. L. Cummings (Eds.), Research in Organizational Behavior: $53-$ 111. Greenwich, CT: JAI. 